This item was submitted to Loughborough's Research Repository by the author.

Items in Figshare are protected by copyright, with all rights reserved, unless otherwise indicated.

\title{
Online estimation of the rotor flux linkage and voltage-source inverter nonlinearity in permanent magnet synchronous machine drives
}

PLEASE CITE THE PUBLISHED VERSION

http://dx.doi.org/10.1109/TPEL.2013.2252024

PUBLISHER

(C) IEEE

VERSION

AM (Accepted Manuscript)

\section{LICENCE}

CC BY-NC-ND 4.0

\section{REPOSITORY RECORD}

Liu, Kan, and Zi-Qiang Zhu. 2019. "Online Estimation of the Rotor Flux Linkage and Voltage-source Inverter Nonlinearity in Permanent Magnet Synchronous Machine Drives". figshare. https://hdl.handle.net/2134/25036. 


\title{
Online Estimation of Rotor Flux Linkage and Voltage Source Inverter Nonlinearity in Permanent Magnet Synchronous Machine Drives
}

\author{
Kan Liu, and Z.Q. Zhu, Fellow, IEEE
}

\begin{abstract}
This paper proposes a method for online estimating the rotor flux linkage and voltage source inverter (VSI) nonlinearity of permanent magnet synchronous machine (PMSM) drives. Thermocouples are employed for measuring the temperature variation of the stator winding in order to obtain the actual value of stator winding resistance. An Adaline estimator is used for online estimation of distorted voltage $\left(V_{\text {dead }}\right)$ due to VSI nonlinearity. Both are subsequently used for the estimation of the rotor flux linkage. The proposed method is experimentally validated on a PMSM drive system and shows good performance in tracking the variation of rotor flux linkage and compensating the VSI nonlinearity.

Index Terms-Nonlinearity compensation, parameter estimation, PMSM, rotor flux linkage, voltage source inverter
\end{abstract}

\section{NOMENCLATURE}

$R \quad$ Stator winding resistance $(\Omega)$.

$L_{d}, L_{q} \quad d q$-axis inductances $(\mathrm{H})$.

$\psi_{m} \quad$ Rotor flux linkage (Wb).

$u_{d}, u_{q} \quad$ Actual $d q$-axis voltages $(\mathrm{V})$.

$i_{d}, i_{q} \quad$ Actual $d q$-axis currents (A).

$i_{a s}, i_{b s}, i_{b s} \quad$ Stator abc phase currents (A).

Denotes a variable specified by PI regulator.

$\wedge \quad$ Denotes an estimated value.

$u_{d}{ }^{*}, u_{q}{ }^{*} \quad d q$-axis reference voltages measured from PI regulators $(\mathrm{V})$.

$\hat{\psi}_{m} \quad$ Estimated rotor flux linkage $(\mathrm{Wb})$.

$V_{\text {dead }} \quad$ Distorted voltage due to inverter nonlinearity in $d q$-axis reference frame $(\mathrm{V})$.

$\omega, \theta \quad$ Electrical angular speed $(\mathrm{rad} / \mathrm{s})$ and rotor position (rad).

$\gamma \quad$ Angles between current vector and $q$-axis (rad).

$D d, D q \quad$ Functions of $\theta$ and the directions of three phase currents.

\section{INTRODUCTION}

$\mathrm{D}$ ue to high power/torque density, permanent magnet (PM) synchronous machines are now widely employed in industrial servo drives, electric/hybrid electric vehicles, and wind power generators, etc. However, there exists a risk of potential irreversible demagnetization in the rotor magnets due to high temperature rise or large demagnetizing current. Since the rotor PM flux linkage decreases as the PM temperature increases, it is desirable to

Manuscript received October 05, 2012. Revised December 10, 2012. Accepted for publication February 27, 2013.

K. Liu and Z.Q. Zhu are with the Department of Electronic and Electrical Engineering, University of Sheffield, UK (e-mail: lkan@live.cn; Z.Q.Zhu@sheffield.ac.uk). estimate the rotor flux linkage value no matter it is for torque control/monitoring or for prevention of PM demagnetization. For example, it is proposed in [37] that the influence from the variation of rotor flux linkage on the computed torque in direct torque control can be compensated by online estimation of rotor flux linkage, in which the accuracy of torque control is significantly improved. In addition, it is reported in [9] that the state of rotor permanent magnet can be monitored instantaneously by using a rotor flux linkage estimator, and a warning signal can be given if magnet demagnetization happens. The estimation of rotor magnet flux for detecting broken magnet is investigated in [40], which shows that there is separation between the estimated magnet flux of the motor with broken magnet and all the other faults and healthy cases. Thus, it is useful to online estimate the rotor flux linkage for PMSM based drive systems and various methods have been recently reported, which can be classified and reviewed as follows.

As detailed in [1], the steady state PMSM equation is rank-deficient for simultaneously estimating the $d q$-axis inductances, the stator winding resistance and the rotor flux linkage. Furthermore, since the estimation is usually based on the parameter model of PMSM, mismatching of unestimated machine parameter values will introduce a significant error into the estimated rotor flux linkage. Thus, in practice, it is required to design a full rank reference model to simultaneously estimate the rotor flux linkage and other parameters that have influence on the estimation of rotor flux linkage.

For example, it is proposed in [2]-[5] to transiently inject flux weakening current $\left(i_{d} \neq 0\right)$ to activate the stator winding resistance term in PMSM $d$-axis equation. With the injected $i_{d} \neq 0$, the values of rotor flux linkage and stator winding resistance can be simultaneously estimated if the $d q$-axis inductance values are set to be their actual values. However, the accuracy of this kind of method is easy to suffer from the variation of voltage source inverter (VSI) nonlinearity, $d q$-axis inductances and rotor flux linkage due to the injected current. Furthermore, the injection of $i_{d} \neq 0$ may introduce unacceptable instability and torque ripples into the drive system.

In addition, it is proposed in [6]-[9] to estimate the stator winding resistance and rotor flux linkage separately by changing PMSM working conditions such as rotor speed [7], [8], and output torque [9]. However, it is not preferable to change the working condition in some applications, which 
require, for example, constant torque/speed control. Furthermore, there also exists significant influence from the VSI nonlinearity and varying stator winding resistance due to temperature change on the estimation accuracy. Thus, the application scope of methods in [6]-[9] may be limited.

For simplicity, it is reported that the combinations of measurement sensors and estimation algorithms can be an easy alternative to solve the rank deficient problem [18], [19]. For example, it is proposed in [18] to add a load test to estimate the rotor flux linkage individually while the method in [19] proposed to bury a thermocouple in the stator winding for the estimation of winding resistance and rotor PM temperature. Compared with [18], it is much cheaper to employ a thermocouple in [19] than to employ a torque transducer. However, the method in [19] needs to inject a high frequency voltage signal into the stator winding and is easy to suffer from the non-ideal behavior of the inverter. Furthermore, it neglects the influence from varying inductance and cannot estimate the actual value of rotor flux linkage.

In this paper, a method for online estimating the PMSM rotor flux linkage and distorted voltage $\left(V_{\text {dead }}\right)$ due to VSI nonlinearity is proposed, which is suitable for most widely used $i_{d}=0$ control. The winding resistance at normal temperature and temperature coefficient of winding resistance are measured before the implementation of proposed method. Thermocouples are employed for measuring the temperature variation in stator winding in order to obtain the actual value of stator winding resistance, which is used for aiding the estimation of rotor flux linkage afterwards. Thus, this method does not need to inject any signals such as $i_{d} \neq 0[1]-[5]$ and DC voltage pulse [10]-[14] or change the PMSM working condition [6]-[9]. Furthermore, it is advanced that the accuracy of proposed rotor flux linkage estimation will not suffer from the variation of $d q$-axis inductances and has taken into account the compensation of estimation error due to VSI nonlinearity thanks to the proposed $V_{\text {dead }}$ estimator, which does not need any device information of the VSI and PM machine. This method is experimentally validated in a field oriented vector control system and shows good performance in tracking the variation of PMSM rotor flux linkage and compensating the VSI nonlinearity.

\section{PMSM MODEL INCLUDING VSI NONLINEARITY}

Assuming that the PMSM has negligible structural asymmetry, iron losses versus copper losses, and magnet motive force harmonics of windings, the $d q$-axis equations of the PMSM are given by:

$$
\begin{aligned}
& \frac{d i_{d}}{d t}=-\frac{R}{L_{d}} i_{d}+\frac{L_{q}}{L_{d}} \omega i_{q}+\frac{u_{d}}{L_{d}} \\
& \frac{d i_{q}}{d t}=-\frac{R}{L_{q}} i_{q}-\frac{L_{d}}{L_{q}} \omega i_{d}+\frac{u_{q}}{L_{q}}-\frac{\psi_{m}}{L_{q}} \omega
\end{aligned}
$$

For machine parameter estimation, the steady-state machine $d q$-axis equations in discrete time domain are usually used for analysis [31]. The steady-state $d q$-axis equations of PMSM are shown as follows:

$$
u_{d}(k)=R i_{d}(k)-L_{q} \omega(k) i_{q}(k)
$$

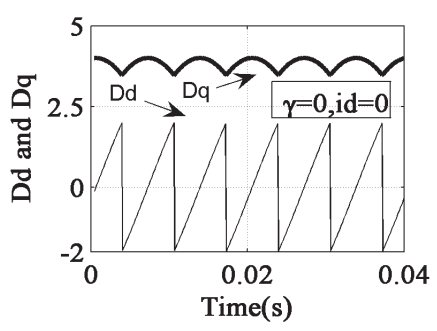

(a)

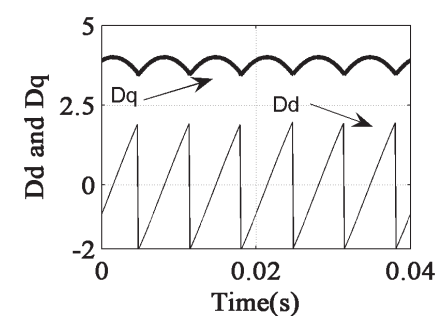

(b)
Fig. 1. Waveforms of $D d$ and $D q$ under $i_{d}=0$ control. (a) Simulated. (b) Actual waveforms of computed $D d$ and $D q, i_{d}$, and $i_{q}$ under $i_{d}=0$ control and $\omega=157 \mathrm{rad} / \mathrm{s}$.

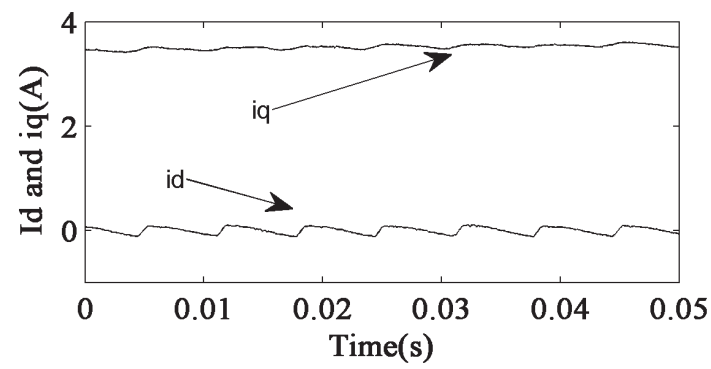

(b)

Fig. 2. Waveforms of $i_{d}$, and $i_{q}$ under $i_{d}=0$ control and $\omega=157 \mathrm{rad} / \mathrm{s}$.

TABLE I

\begin{tabular}{|c|c|c|c|c|c|}
\hline \multirow{2}{*}{$\theta_{e}=\theta+\pi / 2$} & \multicolumn{3}{|c|}{$\operatorname{sign}(i)$} & \multirow{2}{*}{$V_{\text {dead }} D d$} & \multirow{2}{*}{$V_{\text {dead }} D q$} \\
\hline & $i_{a}$ & $i_{b}$ & $i_{c}$ & & \\
\hline$-\pi / 6-\gamma \sim \pi / 6-\gamma$ & 1 & -1 & -1 & $4 V_{\text {dead }} \sin \left(\theta_{e}\right)$ & $4 V_{\text {dead }} \cos \left(\theta_{e}\right)$ \\
\hline$\pi / 6-\gamma \sim \pi / 2-\gamma$ & 1 & -1 & 1 & $4 V_{\text {dead }} \sin \left(\theta_{e}-\pi / 3\right)$ & $4 V_{\text {dead }} \cos \left(\theta_{e}-\pi / 3\right)$ \\
\hline$\pi / 2-\gamma \sim 5 \pi / 6-\gamma$ & -1 & -1 & 1 & $4 V_{\text {dead }} \sin \left(\theta_{e}-2 \pi / 3\right)$ & $4 V_{\text {dead }} \cos \left(\theta_{e}-2 \pi / 3\right)$ \\
\hline $5 \pi / 6-\gamma \sim 7 \pi / 6-\gamma$ & -1 & 1 & 1 & $4 V_{\text {dead }} \sin \left(\theta_{e}-\pi\right)$ & $4 V_{\text {dead }} \cos \left(\theta_{e}-\pi\right)$ \\
\hline $7 \pi / 6-\gamma \sim 3 \pi / 2-\gamma$ & -1 & 1 & -1 & $4 V_{\text {dead }} \sin \left(\theta_{e}-4 \pi / 3\right)$ & $4 V_{\text {dead }} \cos \left(\theta_{e}-4 \pi / 3\right)$ \\
\hline $3 \pi / 2-\gamma \sim 11 \pi / 6-\gamma$ & 1 & 1 & -1 & $4 V_{\text {dead }} \sin \left(\theta_{e}-5 \pi / 3\right)$ & $4 V_{\text {dead }} \cos \left(\theta_{e}-5 \pi / 3\right)$ \\
\hline & & & & $k)+\psi_{m} \omega(k)$ & $(2 b)$ \\
\hline
\end{tabular}

RELATIONSHIP BETWEEN CURRENT DIRECTIONS AND DQ-AXIS DisTORTED VOLTAGE [22]

where ' $k$ ' is the index of the discrete sampling instant. Under $i_{d}=0$ control, (2) can be simplified into:

$u_{d}(k)=-L_{q} \omega(k) i_{q}(k)$

$u_{q}(k)=R i_{q}(k)+\psi_{m} \omega(k)$

The actual PMSM $d q$-axis equations including the distorted voltages due to VSI nonlinearity can be shown as follows [22]-[28]:

$$
\frac{d}{d t}\left[\begin{array}{l}
L_{d} i_{d} \\
L_{q} i_{q}
\end{array}\right]=-R\left[\begin{array}{l}
i_{d} \\
i_{q}
\end{array}\right]+\left[\begin{array}{l}
L_{q} \omega i_{q} \\
-L_{d} \omega i_{d}-\psi_{m} \omega
\end{array}\right]+\left[\begin{array}{l}
u_{d}^{*} \\
u_{q}^{*}
\end{array}\right]+V_{\text {dead }}\left[\begin{array}{l}
D d \\
D q
\end{array}\right]
$$

$D d$ and $D q$ are expressed as follows:

$\left[\begin{array}{c}D d \\ D q\end{array}\right]=2\left[\begin{array}{ccc}\cos (\theta) & \cos \left(\theta-\frac{2 \pi}{3}\right) & \cos \left(\theta+\frac{2 \pi}{3}\right) \\ -\sin (\theta) & -\sin \left(\theta-\frac{2 \pi}{3}\right) & \sin \left(\theta-\frac{\pi}{3}\right)\end{array}\right]\left[\begin{array}{c}\operatorname{sign}\left(i_{a s}\right) \\ \operatorname{sign}\left(i_{b s}\right) \\ \operatorname{sign}\left(i_{c s}\right)\end{array}\right]$

$\operatorname{sign}(i)=\left\{\begin{array}{l}1, i>=0 \\ -1, i<0\end{array}\right.$

As detailed in [22]-[25], assuming that $\gamma$ is the angle between current vector and $q$-axis and $\theta_{e}=\theta+\frac{\pi}{2}$, the distorted voltage due to VSI nonlinearity in $d q$-axis reference frame are shown in Table I.

The simulated waveforms of $D d$ and $D q$ under $i_{d}=0$ control $(\gamma=0)$ is shown in Fig. 1(a), from which it is evident that the 
distorted voltage in $d$-axis reference frame is a zero-mean 6th harmonic component while the distorted voltage in $q$-axis reference frame mainly consists of a DC component and a 6th harmonic component. Fig. 1(b) and Fig. 2 show the actual waveforms of computed $D d$ and $D q$ from (5), $i_{d}$ and $i_{q}$ at $300 \mathrm{r} / \mathrm{min}$, which are from the prototype PMSM shown in Table III of Appendix A.

Comparing Fig. 1(a) with Fig. 1(b), it is evident that the actual waveforms of $D d$ and $D q$ agree very well with the simulated waveforms, which contain the 6 th order harmonic component.

\section{VSI NONLINEARITY ESTIMATION}

In discrete time domain, the steady-state PMSM equation including the distorted voltage due to VSI nonlinearity can be expressed as follows:

$$
\begin{aligned}
& u_{d}{ }^{*}(k)+D d(k) V_{\text {dead }}=R i_{d}(k)-L_{q} \omega(k) i_{q}(k) \\
& u_{q}{ }^{*}(k)+D q(k) V_{\text {dead }}=R i_{q}(k)+L_{d} \omega(k) i_{d}(k)+\psi_{m} \omega(k)
\end{aligned}
$$

As can be seen from (7), the variable $V_{\text {dead }}$, which is related to the distorted voltage due to VSI nonlinearity, will introduce error into the machine parameter estimation. Since $V_{\text {dead }}$ is easy to vary with the current, it is necessary to online estimate and compensate $V_{\text {dead }}$ to ensure the accuracy of estimated PMSM parameter values.

The technology for the online estimation/compensation of the distorted voltage due to VSI nonlinearity has been widely reported [22]-[30], [34]-[36], [41]-[43]. However, most methods need accurate PMSM parameter values [22]-[27], [35], [42], or zero rotor speed [8]. Thus, it is impossible for these methods to estimate the distorted voltage prior to the estimation of PMSM parameter values. In addition, since the distorted voltages in $d q$-axis reference frame are mainly 6th harmonic components [29]-[30], it is reported in [29] and [30] that these distortions can be properly compensated by minimizing the 6th harmonic components. In this section, an Adaline estimator for the online estimation of distorted voltage $V_{\text {dead }}$ due to VSI nonlinearity is designed, which does not need any machine parameter values and is suitable for $i_{d}=0$ control.

As can be seen from Table I, Fig. 1(a) and Fig. 1(b), under $i_{d}=0$ control, it is evident that the high frequency component $D d V_{\text {dead }}$ is zero-mean and its contribution to $d$-axis voltage $\left(u_{d}{ }^{*}(k)\right)$ is only a fluctuation around $0 \mathrm{~V}$. In addition, it is noteworthy that the 6th harmonic component $D d V_{\text {dead }}$ is the dominant term compared with other high frequency components in $d$-axis equation. Thus, under $i_{d}=0$ control, (7a) can be decomposed as follows:

$$
\begin{aligned}
& R i_{d}(k)=R \bar{i}_{d}(k)+R i_{d h}(k)=R i_{d h}(k) \\
& \overline{D d}(k) V_{\text {dead }}=0 \\
& u_{d}{ }^{*}(k)=-D d(k) V_{\text {dead }}-L_{q} \omega(k) i_{q}(k) \\
& u_{d h}{ }^{*}(k)=-D d(k) V_{\text {dead }}-L_{q} \omega_{h}(k) i_{q h}(k) \\
& L_{q} \omega(k) i_{q}(k)=L_{q} \bar{\omega}(k) \bar{i}_{q}(k)+L_{q} \bar{\omega}(k) i_{q h}(k)+L_{q} \omega_{h}(k) \bar{i}_{q}(k) \\
& +L_{q} \omega_{h}(k) i_{q h}(k)
\end{aligned}
$$

In (8), $\overline{i_{d}}, \overline{D d}, \bar{\omega}$ and $\overline{i_{q}}$ are the DC components of $i_{d}$, $D d, \omega$, and $i_{q}$, respectively, while $u_{d h}{ }^{*}, i_{d h}, \omega_{h}$, and $i_{q h}$ are the

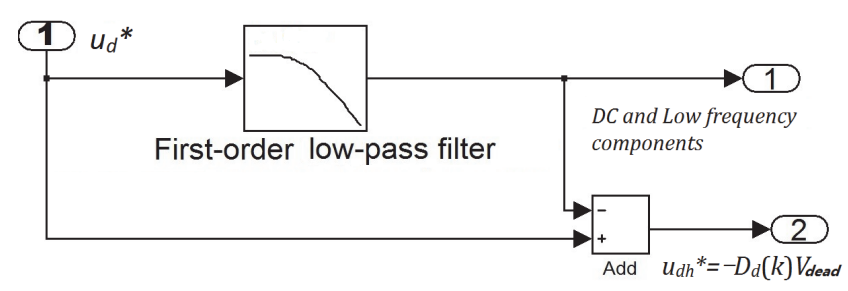

Fig. 3. Obtain high frequency component of $u_{d}^{*}(k)$ by using first-order low-pass filter.

high frequency components of $u_{d}{ }^{*}, i_{d}, \omega$, and $i_{q}$, respectively.

At the steady state of $i_{d}=0$ control, $R \overline{i_{d}}(k)=0$ and terms such as $L_{q} \bar{\omega}(k) i_{q h}(k)$ and $R i_{d h}(k)=R i_{d}(k)$ are in fact part of $D d V_{\text {dead }}$ because $i_{q h}$ and $i_{d h}$ are mainly generated by the 6th harmonic component due to VSI nonlinearity. In addition, $\omega_{h}$ consists of harmonic components due to VSI nonlinearity and mechanical issues such as the rotating friction, load oscillation, and eccentricities, etc, whose FFT analysis (introduced in Appendix C) shows that those harmonic components caused by mechanical issues are at relatively low frequency range and have very small amplitudes. In addition, the 6th harmonic component in $L_{q} \omega_{h}(k) \bar{i}_{q}(k)$ is also caused by VSI nonlinearity and can be regarded as part of $D d V_{\text {dead }}$.

As shown in Fig. 3, the DC component $L_{q} \bar{\omega}(k) \overline{i_{q}}(k)$ of $(8 \mathrm{e})$ and those low frequency components in $L_{q} \omega_{h}(k) \bar{i}_{q}(k)$ can be filtered by a discrete first-order low-pass filter. Thus, there are only two high frequency terms, $D d V_{\text {dead }}$ and $L_{q} \omega_{h}(k) i_{q h}(k)$, left in $(8 \mathrm{~d})$ after filtering. It is also noteworthy that in reality, $L_{q} \omega_{h}(k) i_{q h}(k)$ is quite negligible compared with $D_{d}(k) V_{\text {dead }}$. Thus, it is reasonable that $u_{d h}{ }^{*}$ is approximately equal to $D_{d}(k) V_{\text {dead }}$ and (8d) can be simplified to be (9).

$u_{d h}{ }^{*}(k) \approx-D d(k) V_{\text {dead }}$

Furthermore, since $L_{q} \omega_{h}(k) i_{q h}(k)$ is negligible compared with $D_{d}(k) V_{\text {dead }}$, the influence of the variation of $L_{q}$ on the estimation of $V_{\text {dead }}$ will also be negligible. Taking the PMSM used in this paper as an example, its nominal $q$-axis inductance is $3.24 \mathrm{mH}$. Assuming that the amplitudes of $\omega_{h}(k)$ and $i_{q h}(k)$ are $5 \mathrm{rad} / \mathrm{s}$ and $0.3 \mathrm{~A}$, respectively, and there is a $50 \%$ increase in $L_{q}$, the amplitude of $L_{q} \omega_{h}(k) i_{q h}(k)$ will be $5 \times 0.3 \times 1.5 \times 3.24 \mathrm{e}-3=7.29 \mathrm{mV}$, which is quite negligible compared with the estimated amplitude of $D_{d}(k) V_{\text {dead }}$ $(2 \times 0.25 \mathrm{~V}=0.5 \mathrm{~V})$ as will be shown in Fig. 5 .

Thus, from the above analysis, $V_{\text {dead }}$ can be estimated from (9). Since Adaline Neural Network (NN) algorithm is simple and low cost in computation, it is used to design all the estimators in the proposed estimation. The design of $V_{\text {dead }}$ estimator and related design processes are described in Appendix B. Assuming $X_{i}=-D d(k), W_{i}=\hat{V}_{\text {dead }}$, $O(k)=-\hat{V}_{\text {dead }} D d(k)$ and $d(k)=u_{d h}{ }^{*}(k)$, the Adaline estimator of $V_{\text {dead }}$ can be expressed as follows:

$\hat{V}_{\text {dead }}(k+1)=\hat{V}_{\text {dead }}(k)-2 \eta D d(k)(d(k)-O(k))$

where $\eta$ is the convergence factor. $O(k)$ and $\hat{V}_{\text {dead }}$ are the output of variable model and estimated $V_{\text {dead }}$, respectively. 


\section{ROTOR FLUX LINKAGE ESTIMATION AND EXPERIMENTAL VERIFICATION}

\section{A. Design of Rotor Flux Linkage Estimator}

Under $i_{d}=0$ control, (7b) can be simplified as:

$u_{q}^{*}(k)+D q(k) V_{\text {dead }}=R i_{q}(k)+\psi_{m} \omega(k)$

From (11), it is evident that the value of rotor flux linkage can be estimated on condition that the values of $V_{\text {dead }}$ and $R$ can be accurately obtained. $V_{\text {dead }}$ can be estimated from $d$-axis equation by using (10). Since the winding resistance $R$ is a linear function of winding temperature, two sets of thermocouples are buried into two different sides of PMSM stator winding and the actual value of winding resistance can be computed by the measured average temperature through (12).

$R=R_{0}+\mathrm{TCR}\left(T_{2}-T_{0}\right)$

$R_{0}, R$ and TCR are the winding resistance value at room temperature $\left(T_{0}=22^{\circ} \mathrm{C}\right)$, actual winding resistance value at temperature $T_{2}$ and temperature coefficient of winding resistance. Thus, under $i_{d}=0$ control, assuming $X_{i}=\omega(k)$, $O(k)=\hat{\psi}_{m}(k) \omega(k)$ and $d(k)=u_{q}{ }^{*}(k)+D q(k) V_{\text {dead }}-R i_{q}(k)$, the Adaline estimator of rotor flux linkage can be derived from (11) and shown as follows.

$\hat{\psi}_{m}(k+1)=\hat{\psi}_{m}(k)+2 \eta \omega(k)\left(d_{q}(k)-O(k)\right)$

\section{B. Compensation of VSI Nonlinearity}

It is known that $V_{\text {dead }}$ represents the VSI nonlinearity which should be well compensated or minimized in real application. However, it is known that the response of drive system to the compensation of $V_{\text {dead }}$ is not linear and an online tuning process is usually needed for the minimization of $V_{\text {dead }}$. For example, Zhao [30] proposed an online tuning scheme to minimize the 6th harmonics in $d q$-axis currents for the compensation of VSI nonlinearity. Similarly, Park and Sul [34] proposed to use trapezoidal voltage to compensate the inverter nonlinearity, whose trapezoidal angle was real time tuned by an integral controller.

In this research, since $V_{\text {dead }}$ can be real-time estimated by (10), the VSI nonlinearity can be well compensated through the minimization of estimated $V_{\text {dead }}$. The field oriented vector control system shown in Fig. 4(b) is employed for validation. Assuming that $\tilde{V}_{\text {dead }}, V_{\text {thr }}, \zeta$ and $\gamma$ are the estimated $V_{\text {dead }}$ by (10), threshold voltage of minimized $V_{\text {dead }}$, tuning factor and gain factor of $V_{\text {dead }}$, respectively, the schematic diagram of related minimization process is depicted in Fig. 4(a) and the adjustments of the tuning factor $\zeta$ and gain factor $\gamma$ are introduced as follows:

a. Initialize $V_{t h r}, \zeta$ and $\gamma$. For example, in this research, $\zeta$ and $\gamma$ are initialized to be $1.0 \mathrm{e}-4$ and 0.1 , respectively, while $V_{t h r}$ is set to $1.0 \mathrm{e}-4 \mathrm{~V}$, which is quite close to 0 .

b. If $\left|\tilde{V}_{\text {dead }}\right|<V_{\text {thr }}$, it means that the VSI nonlinearity has been well compensated and the value of $\gamma$ will be kept as a constant for compensation.

c. If $\left|\tilde{V}_{\text {dead }}\right|>V_{t h r}$, it means that the VSI nonlinearity is not well compensated. The value of $\gamma$ will be increased or decreased in each step of computation until it reaches the point that $\left|\tilde{V}_{\text {dead }}\right|<V_{t h r}$. The rule for decreasing or increasing $\gamma$ is described in Fig. 4(a).

d. The real-time computed $D d \gamma \tilde{V}_{\text {dead }}$ and $D q \gamma \tilde{V}_{\text {dead }}$ will be added to the output of $d q$-axis PI regulators for compensation.

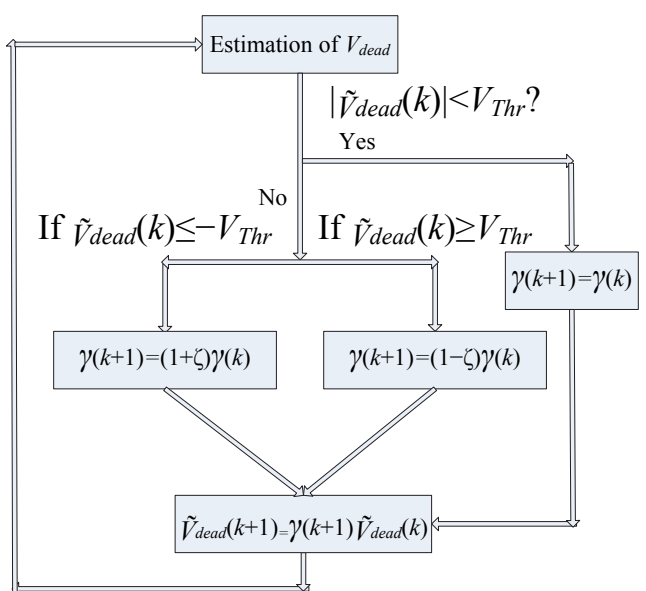

(a)

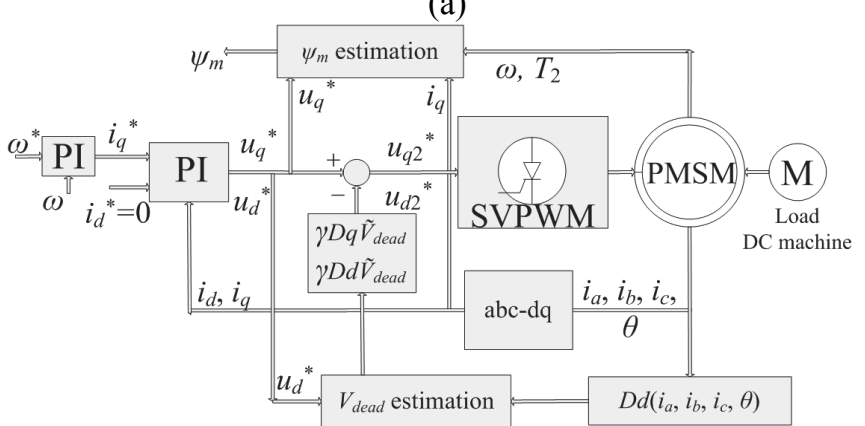

(b)

Fig. 4. Process of VSI nonlinearity compensation and used control system. (a) Compensating VSI nonlinearity by minimizing $V_{\text {dead }}$. (b) Field oriented vector control system with proposed estimation/compensation method.

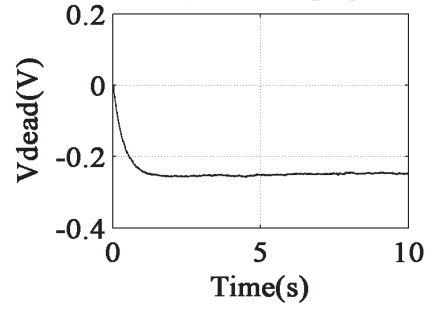

(a)

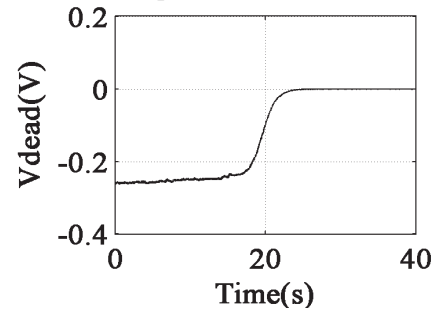

(b)
Fig. 5. Estimation and compensation of VSI nonlinearity. (a) Estimation of VSI nonlinearity. (b) Compensation of VSI by minimizing $V_{\text {dead }}$.

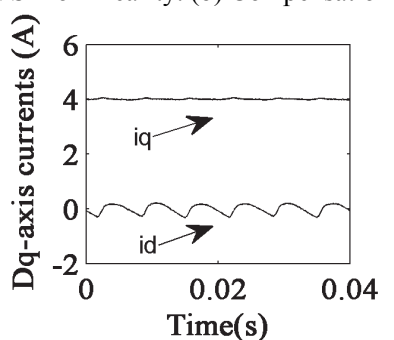

(a)

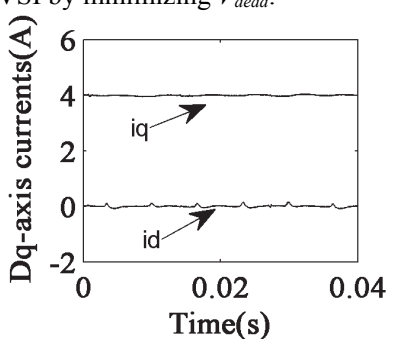

(b)
Fig. 6. Dq-axis currents with and without proposed compensation of VSI nonlinearity. (a) Without compensation. (b) With proposed compensation.

e. Go back to step b.

It should be noted that the value of $\zeta(>0)$ can control the speed of the minimization of $\tilde{V}_{\text {dead }}$ and an abrupt change may be introduced into the control system if $\zeta$ is too big. Thus, $\zeta$ is usually set to a small value (1.0e-4 in this paper) to smooth the process of minimizing $\tilde{V}_{\text {dead }}$.

The PMSM detailed in Appendix A will be employed for validating the performance of proposed method. Fig. 5 shows the estimation and compensation of $V_{\text {dead }}$ and it is obvious that $V_{\text {dead }}$ can be minimized to be almost 0 . Consequently, the VSI nonlinearity is well compensated after this minimization. Figs. 6-8 are the measured currents at $300 \mathrm{rpm}$ in different 
reference frames with and without the proposed compensation. It is obvious that with the proposed compensation, the $d q$-axis currents will be with less 6th harmonics while the phase current will be more sinusoidal. Furthermore, it is evident that the circle of $\alpha \beta$-axis currents shown in Fig. 7 (a) and (b) will be more orbicular with the proposed compensation. It is also manifest from the FFT results depicted in Fig. 7(c) and (d) that the 5th and 7th harmonics in $\alpha$-axis current are minimized to be negligible, of which the sum is the 6th harmonic.

\section{Rotor Flux Linkage Estimation at Normal} Temperature

With aiding from the estimated $V_{\text {dead }}$ and computed winding resistance $R$, the rotor flux linkage can be finally estimated by (13). The complete diagram of proposed method is shown in Fig. 9 and the whole estimation are divided into three steps: (1). At standstill, the stator winding resistance value $\left(R_{0}\right)$ at normal temperature $\left(T_{0}\right)$ is measured by milliohm meter and two sets of thermocouple are employed for measuring the variation of stator winding temperature $\left(T_{2}\right)$, which will be used for real time computing the actual value of stator winding resistance $(R)$. (2). The value of $V_{\text {dead }}$ of distorted voltage due to VSI nonlinearity is online estimated from the $d$-axis equation and employed for the compensation of inverter nonlinearity. (3). The rotor flux linkage is finally estimated from the $q$-axis equation with the aiding from computed winding resistance and $V_{\text {dead }}$.

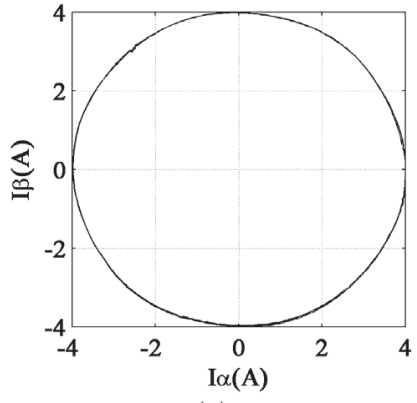

(a)

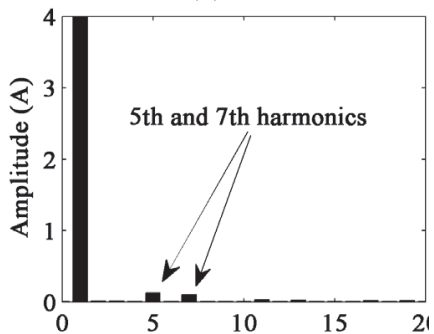

(c)

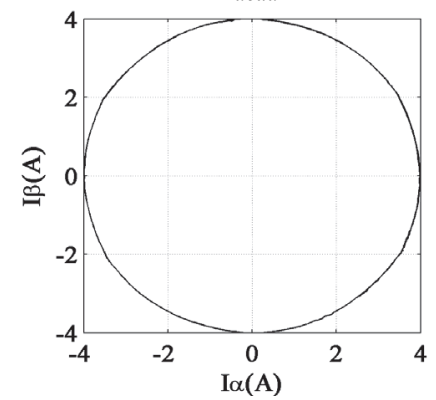

(b)

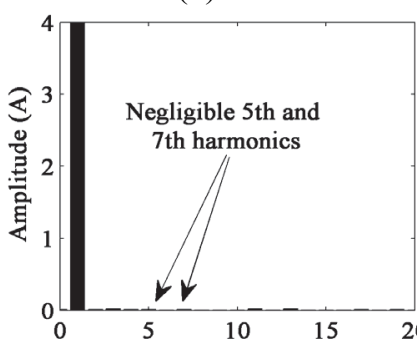

(d)
Fig. 7. $\alpha \beta$-axis currents with and without proposed compensation of VSI nonlinearity. (a) Without compensation. (b) With proposed compensation. (c) FFT result of $\alpha$-axis current without compensation. (d) FFT result of $\alpha$-axis current with proposed compensation.

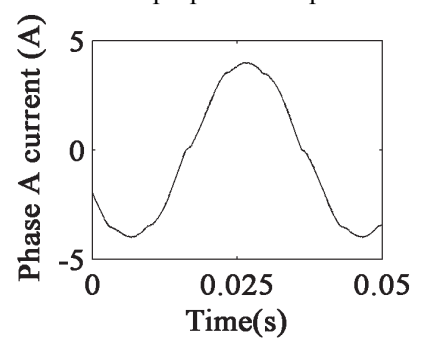

(a)

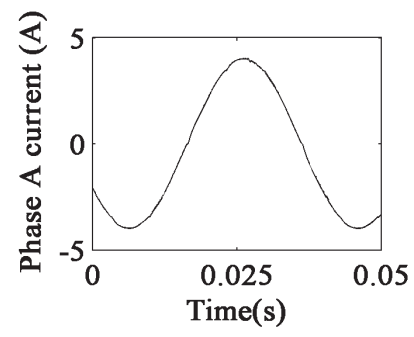

(b)
Fig. 8. Phase A current with and without proposed compensation of VSI nonlinearity. (a) Without compensation. (b) With proposed compensation.

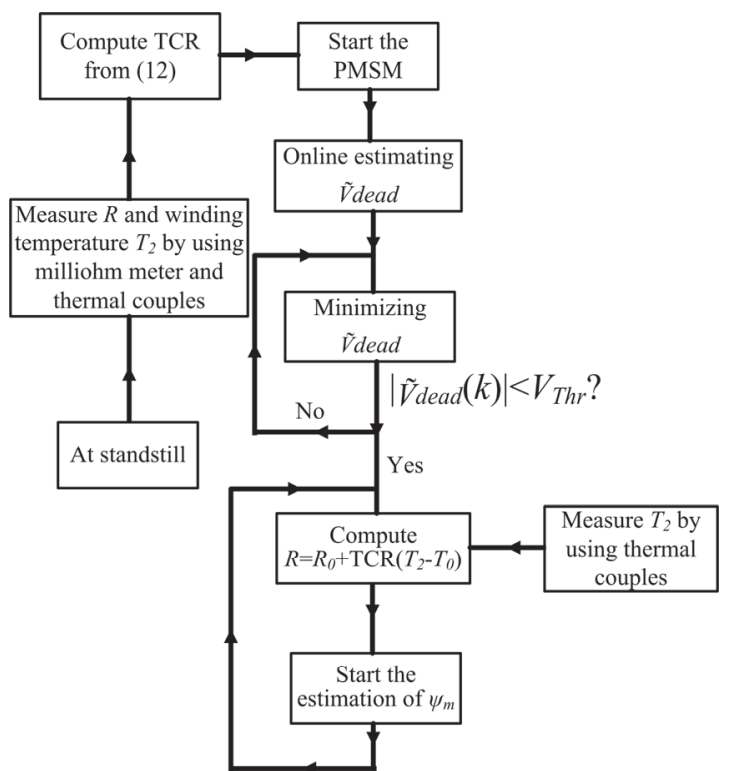

Fig. 9. Complete diagram of proposed method.

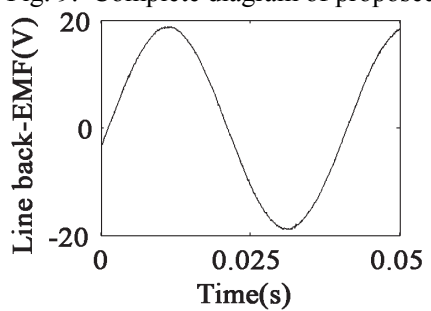

(a)

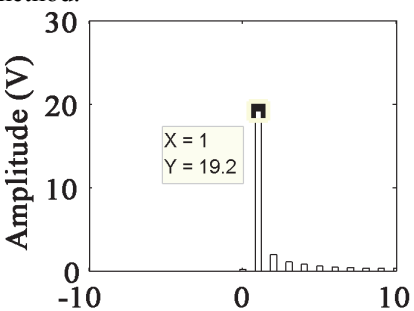

(b)
Fig. 10. Line back-EMF at no-load condition and FFT result. (a) Line back-EMF at 300rpm and normal temperature. (b) Amplitude of fundamental frequency component of line back-EMF.

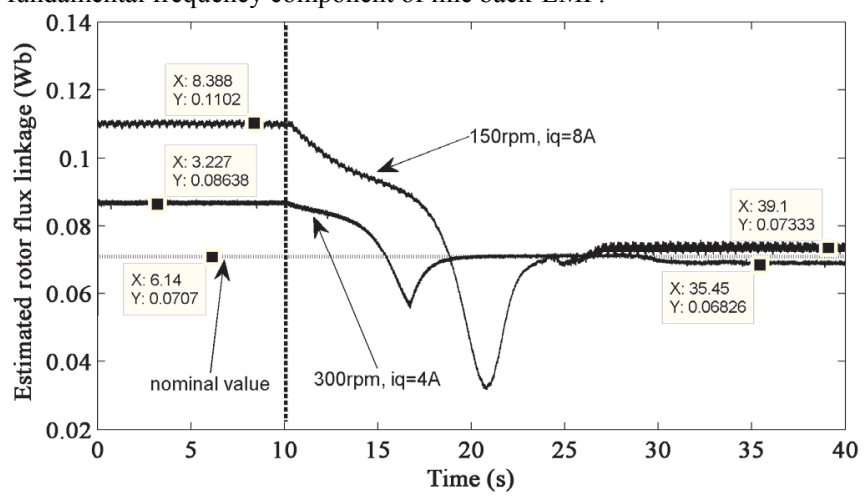

Fig. 11. Estimated rotor flux linkage with and without proposed compensation at normal temperature.

To confirm the accuracy of this method, the PMSM is drawn by a DC machine and the rotor flux linkage at no-load condition will be computed from the measured line back-EMF for comparison. From Fig. 10, the amplitude of the fundamental frequency component of line back-EMF is obtained by using FFT and the rotor flux linkage at no-load condition is derived below:

$$
\frac{19.23 \mathrm{~V} \times 60 \mathrm{~s}}{2 \pi \times \sqrt{3} \times 5 \times 300 \mathrm{rpm}}=70.7 \mathrm{mWb}
$$

The estimation of rotor flux linkage under different working conditions is depicted in Fig. 11, in which the estimation and compensation of $V_{\text {dead }}$ are started after $\mathrm{t}=10 \mathrm{~s}$. From Fig. 11, it is obvious that the estimated rotor flux linkage at $300 \mathrm{rpm}(68.3 \mathrm{mWb})$ is close to that at no-load condition $(70.7 \mathrm{mWb})$ and the slight decrease in rotor flux linkage $(70.7-68.3=2.4 \mathrm{mWb})$ can be explained that it is caused by the variation of flux density due to on-load. 


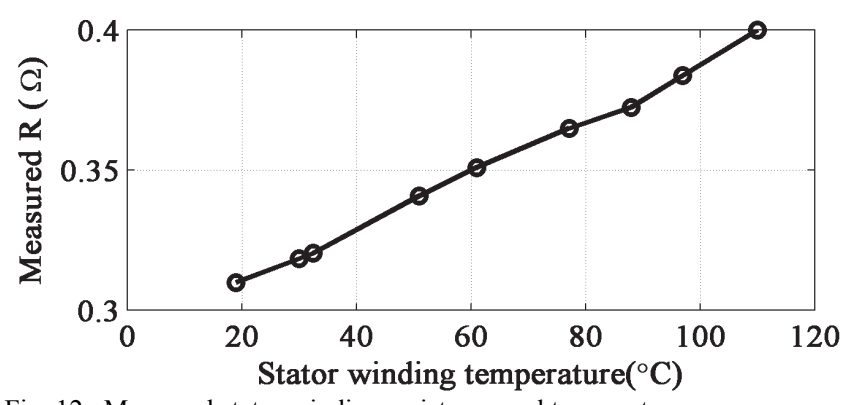

Fig. 12. Measured stator winding resistance and temperature.

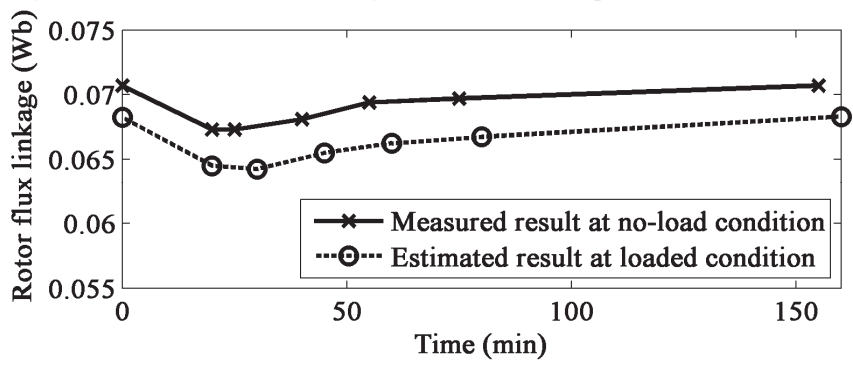

(a)

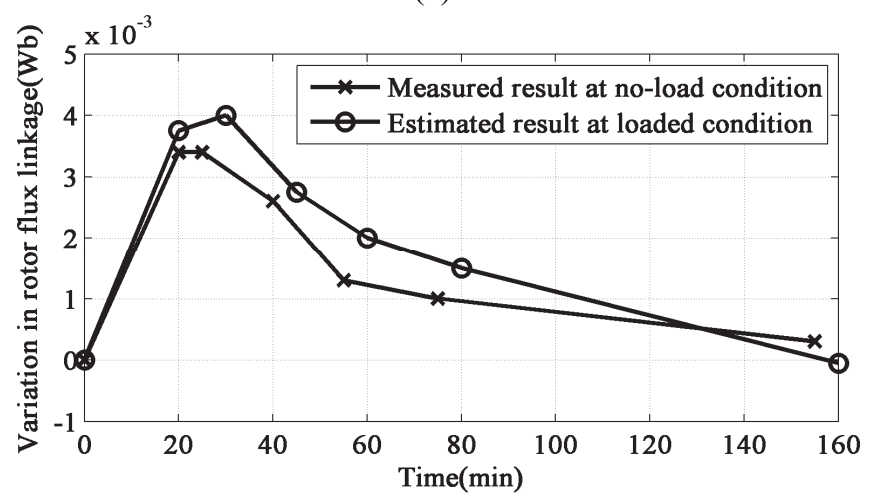

(b)

Fig. 13. Comparison between estimated and measured rotor flux linkage at different time points. (a) Real-time estimated/measured rotor flux linkage. (b) Variation in rotor flux linkage.

However, the estimated rotor flux linkage at 150rpm $(73.3 \mathrm{mWb})$ is slightly larger than that at no-load condition $(70.7 \mathrm{mWb})$, which is contrary to the basic theory that the rotor flux linkage at loaded condition should be smaller than that at no-load condition. This estimation error can be explained that there are still influences from other nonlinearities such as non-ideal position measurement, current offsets and non-ideal measurement of DC bus voltage. Since the back EMF of the PMSM used for experimental validation is relatively small at low speed (less than $8 \mathrm{~V}$ at $150 \mathrm{rpm}$ ), the accuracy of estimated rotor flux linkage at $150 \mathrm{rpm}$ will suffer from these unestimated nonlinearities significantly and present a relatively big estimation error $(73.3-70.7=2.6 \mathrm{mWb})$ even if the VSI nonlinearity is well compensated. The influences from these unestimated nonlinearities will be negligible when the estimation of rotor flux linkage is at a relatively high speed, at which a relatively high ratio of back EMF versus other nonlinearities can be achieved. For example, the estimated rotor flux linkage at $300 \mathrm{rpm}$ shows a much higher accuracy than that at 150rpm.

Furthermore, from Fig. 11, it also shows that the difference between the results with and without the compensation of $V_{\text {dead }}(86.4-68.3=18.1 \mathrm{mWb})$ at $300 \mathrm{rpm}$ is almost half of that $(110.2-73.3=36.9 \mathrm{mWb})$ at $150 \mathrm{rpm}$. This can be explained that the variation of $V_{\text {dead }}$ at different working conditions is relatively small but the ratio of $D q V_{\text {dead }}$ versus $\psi_{m} \omega$ will approximately decrease twice when the rotor speed increases from $150 \mathrm{rpm}$ to $300 \mathrm{rpm}$.

\section{Temperature Rise in Magnet}

It is known from [1] that under $i_{d}=0$ control, the terms such as stator winding resistance and rotor flux linkage only exist in the $q$-axis equation if the PMSM is at steady state. Thus, the estimation of stator winding resistance should be together with or prior to the estimation of rotor flux linkage [10]-[17], [44]-[46]. Otherwise, the estimation will face the rank-deficient problem and the accuracy of the estimated rotor flux linkage will suffer from the mismatched stator winding resistance value used in the estimator [1]. For estimating the stator winding resistance under loaded condition, the injection of perturbation signals such as $i_{d} \neq 0$ [1]-[5] or DC voltage [10]-[14] is usually needed. However, this kind of method is easy to introduce instability and torque ripples into the drive system and is not preferable in constant torque/speed control. Thus, for simplicity, thermal couples are employed for the measurement of winding temperature with which the winding resistance is real-time computed and used for aiding the estimation of rotor flux linkage. It is noteworthy that in real application, thermocouples are widely employed for the temperature monitoring of commercial electrical machines, particularly for large machines. For example, there are 14 thermocouple temperature probes in a 247 MVA synchronous generator [39].

To confirm the accuracy of proposed method in tracking the variation of rotor flux linkage under different temperatures, a comparison experiment is designed and organized as follows:

1) A heater is used to keep on heating the PMSM for 20 minutes and then left for natural cooling.

2) At $\mathrm{t}=20,25,40,55,75,155 \mathrm{~min}$, the DC machine will be started to draw the PMSM and its rotor speed is fixed to 300rpm while the line back-EMF of PMSM at no-load condition will be recorded by using a scope. The rotor flux linkage at no-load condition can be computed from these measured data with aiding from FFT.

3) At $t=20,30,45,60,80,160 \mathrm{~min}$, the PMSM will be loaded and the rotor flux linkage at loaded condition will be online estimated with aiding from the measured stator winding temperatures.

The actual stator winding resistance at different temperatures is measured and shown in Fig. 12, which varies with the measured winding temperature linearly and the coefficient of temperature TCR can be obtained afterwards. The experimental results of step 2 and 3 are plotted in Fig. 13, which show that the proposed method has good performance in tracking the variation of rotor flux linkage. As can be seen from Fig. 13, the estimated rotor flux linkage will vary from $68.3 \mathrm{mWb}$ to $64.5 \mathrm{mWb}$ after 20 minutes' heating. However, since there is a heat transfer delay between the stator and rotor PM, there will be a heat balance between the stator and rotor and the rotor flux linkage value will go on decreasing and be $64.3 \mathrm{mWb}$ after 10 minutes' cooling. Then, the rotor flux linkage will slowly increase with the decrease in permanent magnet temperature and will reach to its normal value at last. 


\section{CONCLUSIONS}

A new scheme for the online estimation of PMSM rotor flux linkage and VSI nonlinearity is proposed, which can be used for the condition monitoring of rotor permanent magnet. Compared with existing methods for estimating rotor flux linkage, the proposed method does not need to inject any perturbation signals and has taken into account the estimation and compensation of the distorted voltage due to VSI nonlinearity. It is experimentally validated on a prototype surface mounted PMSM and shows good performance. Thus, its application in interior PMSM drive system still needs further investigation. Furthermore, since it is only suitable for $i_{d}=0$ control, the estimation for $i_{d} \neq 0$ control will be investigated and reported in future.

\section{Appendix A - Test Bench and Machines}

The PMSM driven by a DSPACE based vector control system is shown in Fig. 14 and will be used for experimental verification, whose design parameters are shown in Table II. In addition, the parameter configuration of employed voltage source inverter is shown in Table III, which is a Semikron SEMIX stack with SEMIX71GD12E4s IGBT modules.

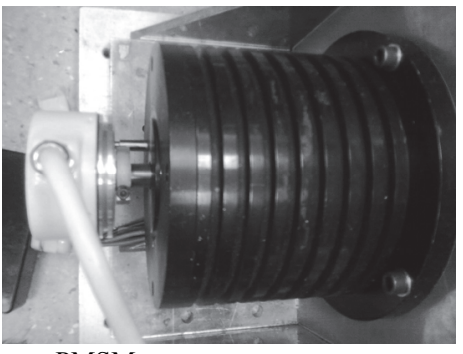

Fig. 14. Prototype PMSM.

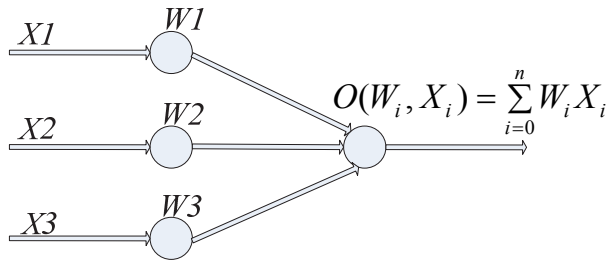

Fig. 15. Structure of an Adaline NN.

TABLE II

DESIGN PARAMETERS AND SPECIFICATION OF PMSM

\begin{tabular}{ll}
\hline Rated current & $10 \mathrm{~A}$ \\
Rated speed & $400 \mathrm{rpm}$ \\
DC link voltage & $36 \mathrm{~V}$ \\
Nominal phase resistance $\left(T=25^{\circ} \mathrm{C}\right)$ & $0.320 \Omega$ \\
Nominal self inductance & $2.91 \mathrm{mH}$ \\
Nominal mutual inductance & $-0.330 \mathrm{mH}$ \\
Nominal $d$-axis inductance & $3.24 \mathrm{mH}$ \\
Nominal $q$-axis inductance & $3.24 \mathrm{mH}$ \\
Amplitude of flux induced by magnets & $70.7 \mathrm{mWb}$ \\
Number of pole pairs & 5 \\
\hline
\end{tabular}

TABLE III

TYPICAL ELECTRICAL PARAMETERS OF VSI (FROM SEMIX71GD12E4S DATASHEET)

$\begin{array}{lr}\text { Turn on delay } T_{\text {on }} & 0.160 \mu \mathrm{s} \\ \text { Turn on/off delay } T_{\text {off }} & 0.433 \mu \mathrm{s} \\ \text { Hardware dead time } & 4 \mu \mathrm{s} \\ \text { Switch control dead time } t_{d} & 2 \mu \mathrm{s} \\ \text { Voltage drop of the active switch }\left(25^{\circ} \mathrm{C}\right) V_{c e} & 1.85 \mathrm{~V} \\ \text { Voltage drop of the freewheeling } & 2.2 \mathrm{~V} \\ \quad \text { diode }\left(25^{\circ} \mathrm{C}\right) V_{d} & 0-650 \mathrm{~V} \\ \text { Supply voltage range } & \end{array}$

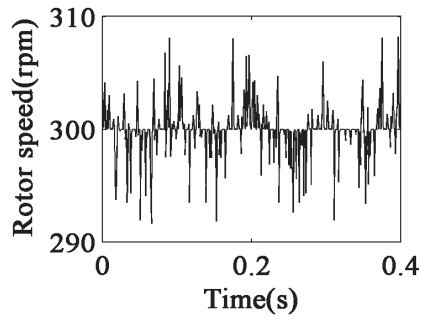

(a)

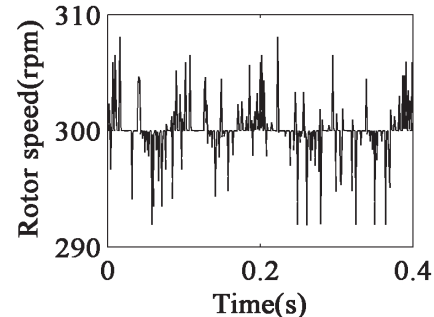

(b)
Fig. 16. Measured rotor speed with and without proposed VSI nonlinearity compensation $\left(i_{d}=0 \mathrm{~A}, i_{q}=4 \mathrm{~A}, 300 \mathrm{rpm}\right)$. (a) Without compensation. (b) With proposed compensation.

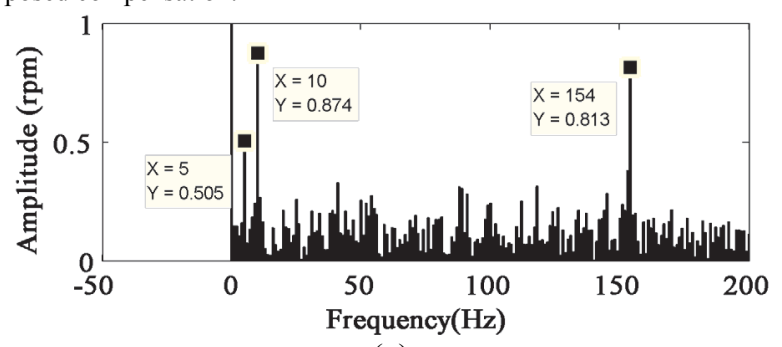

(a)

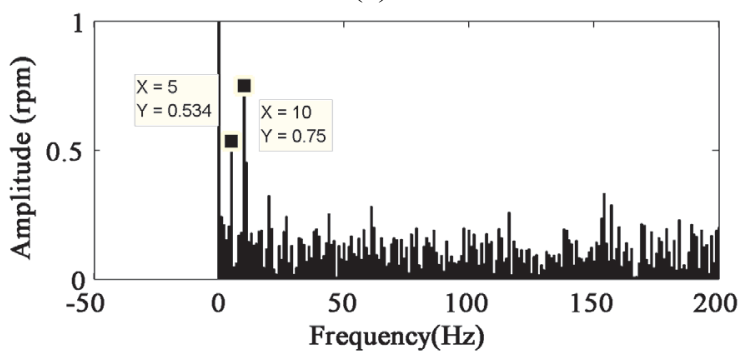

(b)

Fig. 17. FFT analysis for rotor speed with and without proposed VSI nonlinearity compensation $\left(i_{d}=0 \mathrm{~A}, i_{q}=4 \mathrm{~A}, 300 \mathrm{rpm}\right)$. (a) Without compensation. (b) With proposed compensation.

\section{Appendix B - Design Estimators by Adaline NN}

Since Adaline NN algorithm [33] requires few computations and can be used for parameter estimation of machines [32], it is used to design all the estimators throughout the paper. The mathematical model of Adaline NN can be expressed as follows:

$O\left(W_{i}, X_{i}\right)=\sum_{i=0}^{n} W_{i} X_{i}$

where $W_{i}$ is the net weight and $X_{i}$ is the input signal. The activation function $O\left(W_{i}, X_{i}\right)$ of the network output node is a linear function.

The structure of Adaline NN [33] is shown in Fig. 15. As can be seen from (B.1) and Fig. 15, if $d(k)$ is the sampled target output, the weight adjustment can be obtained via least mean square (LMS) method:

$W_{i}(k+1)=W_{i}(k)+2 \eta X_{i}(d(k)-O)$

where $\eta$ is the convergence factor which adjusts the convergence speed. If the parameter to be estimated can be mathematically expressed in the form of general Adaline NN structure, as shown in Fig. 15, its estimator can be directly derived from (B.2) by comparing its net structure with the general Adaline NN structure.

In LMS theory, the convergence factor $\eta$ should be limited to a proper range of values, which can ensure the stability and convergence of estimator (B.2) [33]. A general useful range for $\eta$ is

$0<2 \eta\left|X_{i}\right|^{2}<1$ 
For estimator (10), $X_{i}=-D d(k)$ and it is obvious from Fig. 1 that the amplitude of $|D d(k)|=2$. Thus, the convergence factor $\eta$ of (10) should be $0<\eta<0.125$. Similarly, for estimator (13), $X_{i}=\omega(k)<=209.4$ because the rated speed of used PMSM is 400rpm. Thus, the convergence factor $\eta$ of (13) should be $0<\eta<1.1403 \mathrm{e}-5$. In this paper, the convergence factors of (10) and (13) are set to $1.0 \mathrm{e}-5$ and $1.0 \mathrm{e}-6$, respectively.

\section{Appendix C - FFT analysis for rotor speed}

Fig. 16 shows the measured rotor speed with and without proposed VSI nonlinearity compensation. From the FFT analysis results shown in Fig. 17, there are three main harmonic components $(5 \mathrm{~Hz}, 10 \mathrm{~Hz}$ and $154 \mathrm{~Hz})$ in the measured rotor speed without proposed compensation. It is known that the rotor speed is $300 \mathrm{rpm}(5 \mathrm{r} / \mathrm{s})$ and the pole pair number is 5 . Thus, the $5 \mathrm{~Hz}$ and $10 \mathrm{~Hz}$ components are related to mechanical issues such as the rotating friction, load oscillation, and eccentricities, etc. In addition, since the VSI nonlinearity is a 6th harmonic component and its frequency at $300 \mathrm{rpm}$ is $150 \mathrm{~Hz}$ in theory, the $154 \mathrm{~Hz}$ component shown in Fig. 17(a) should be mainly related to the VSI nonlinearity and can be compensated by the proposed nonlinearity compensation, which is depicted in Fig. 17(b).

\section{REFERENCES}

[1] K. Liu, Q. Zhang, J.T. Chen, Z.Q. Zhu, J. Zhang, and A.W. Shen, "Online multiparameter estimation of nonsalient-pole PM synchronous machines with temperature variation tracking," IEEE Trans. Ind. Electron., vol. 58, no. 5, pp. 1776-1788, May 2011.

[2] S.J. Underwood, and I. Husain, "On-line parameter estimation and adaptive control of permanent magnet synchronous machines," IEEE Trans. Ind. Electron., vol. 57, no. 7, pp. 2435-2443, Jul. 2010.

[3] M.N. Uddin, and M.M.I. Chy, "Online parameter-estimation-based speed control of PM AC motor drive in flux-weakening region," IEEE Trans. Ind. Applicat., vol. 44, no. 5, pp. 1486-1494, Sep./Oct. 2010.

[4] K.W. Lee, D.H. Jung, and I.J. Ha, "An online identification method for both stator resistance and back-EMF coefficient of PMSMs without rotational transducers," IEEE Trans. Ind. Electron., vol. 51, no. 2, pp. 507-510, Apr. 2004.

[5] Z.Q. Zhu, X. Zhu, and P.D. Sun, "Estimation of winding resistance and PM flux-linkage in brushless AC machines by reduced-order extended Kalman Filter," in Proc. 2007 IEEE International Conf. on Networking Sensing and Control, 2007, pp. 740-745.

[6] S.B. Lee, "Closed-loop estimation of permanent magnet synchronous motor parameters by PI controller gain tuning," IEEE Trans. Energy Convers., vol. 21, no. 4, pp. 863-870, Dec. 2006.

[7] A. Piippo, M. Hinkkanen, and J. Luomi, "Adaptation of motor parameters in sensorless PMSM drives," IEEE Trans. Ind. Applicat., vol. 45, no. 1, pp. 203-212, Jan./Feb. 2009.

[8] S. Morimoto, M. Sanada, and Y. Yakeda, "Mechanical sensorless drives of IPMSM with online parameter identification," IEEE Trans. Ind. Applicat., vol. 42, no. 5, pp. 1241-1248, Sept./Oct. 2006.

[9] R. Ramakrishnan, R. Islam, M. Islam, and T. Sebastian, "Real time estimation of parameters for controlling and monitoring," in Proc. IEEE International Electric Machines and Drives Conf., Miami, Florida, 2009, pp. 1194-1199.

[10] P.J. Zhang, B. Lu, and T.G. habetler, "A remote and sensorless stator winding resistance estimation method for thermal protection of soft-starter-connected induction machines," IEEE Trans. Ind. Electron. vol. 55, no. 10, pp. 3611-3618, Oct. 2008

[11] S.B. Lee, and T.G. Habetler, "An online stator winding resistance estimation technique for temperature monitoring of line-connected induction machines," IEEE Trans. Ind. Applicat., vol. 39, no. 3, pp. 685-694, Mar. 2003

[12] S.B. Lee, and T.G. Habetler, "A remote and sensorless thermal protection scheme for small line-connected ac machines," IEEE Trans. Ind. Applicat., vol. 39, no. 5, pp. 1323-1332, Sep./Oct. 2008.

[13] S.D. Wilson, P.G. Stewart, and B.P. Taylor, "Methods of resistance estimation in permanent magnet synchronous motors for real-time thermal management," IEEE Trans. Energy Convers., vol. 25, no. 3, pp. 698-707, Sep./Oct. 2008

[14] S.D. Wilson, G.W. Jewell, and P.G. Stewart, "Resistance estimation for temperature determination in PMSMs through signal injection," in Proc. IEEE International Electric Machines and Drives Conf., San Antonio, TX, 2005, pp. 735-740.

[15] S. Ichikawa, M. Tomita, S. Doki, and S. Okuma, "Sensorless control of permanent-magnet synchronous motors using online parameter identification based on system identification theory," IEEE Trans. Ind. Electron., vol. 53, no. 2, pp. 363-372, Apr. 2006.

[16] M. Rashed, P.F.A. Macconnell, A.F. Stronach, and P. Acarnley, "Sensorless indirect-rotor-field-orientation speed control of a permanent-magnet synchronous motor with stator-resistance estimation," IEEE Trans. Ind. Electron., vol. 54, no. 3, pp. 1664-1675,Jun. 2007.

[17] X. Xiao, C.M. Chen, and M. Zhang, "Dynamic permanent magnet flux estimation of permanent magnet synchronous machines," IEEE Trans. Applied Superconductivity, vol. 20, no. 3, pp. 1085-1088, Mar. 2010.

[18] M.A. Jabbar, J. Dong, and Z. Liu, "Determination of machine parameters for internal permanent magnet synchronous motors," in Proc. Power Electron., Machines and Drives, 2004, vol. 2, pp. 805-810

[19] D.D. Reigosa, F. Briz, P. Gacia, J.M. Guerrero, and M.W. Degner, "Magnet temperature estimation in surface PM machines using high-frequency signal injection," IEEE Trans. Ind. Applicat., vol. 46, no. 4, pp. 1468-1475, Jul./Aug. 2010.

[20] J.W. Choi, and S.K. Sul, "Inverter output voltage synthesis using novel dead-time compensation," IEEE Trans. Power Electron., vol. 11, no. 2, pp. 221-227, Mar. 1996.

[21] R. Munoz, and Thomas A. Lipo, "On-line dead-time compensation technique for open-loop PWM-VSI drives," IEEE Trans. Power Electron. , vol. 14, no. 4, pp. 683-689, July. 1999.

[22] H. S. Kim, K. H. Kim, and M. J.Youn, "On-line dead-time compensation method based on time delay control," IEEE Trans. Contr. Syst. Technol., vol. 11, no. 2, pp. 279-285, Mar./Apr. 2003.

[23] H. S. Kim, H. T. Moon, and M. J.Youn, "On-line dead-time compensation method using disturbance observer," IEEE Trans. Power Electron., vol. 18, no. 6, pp. 1336-1345, Nov. 2003.

[24] H.W. Kim, H. S. Kim, M. J. Youn, and K.W. Cho, "On-line observation and compensation of voltage distortion in PWM VSI for PMSM," IEE Proc. B, Electron. Power Appl., vol. 151, no. 5, pp. 534-542, Sep. 2004

[25] S.H. Hwang, and J.M. Kim, "Dead time compensation method for voltage-fed PWM inverter," IEEE Trans. Energy Convers., vol. 25, no. 1, pp. 1-10, Mar. 2010

[26] H.W. Kim, M.J. Youn, K.Y. Cho, and H.S. Kim, "Nonlinearity estimation and compensation of PWM VSI for PMSM under resistance and flux linkage uncertainty," IEEE Trans. Contr. Syst. Technol., vol. 14, no. 4, pp. 589-601, July. 2006.

[27] S.Y. Kim, W. Lee, M.S. Rho, and S.Y. Park, "Effective dead-time compensation using a simple vectorial disturbance estimator in PMSM drives," IEEE Trans. Ind. Electron., vol. 57, no. 5, pp. 1609-1614, May, 2010.

[28] K. Liu, Z.Q. Zhu, Q. Zhang, and J. Zhang, "Influence of nonideal voltage measurement on parameter estimation in permanent magnet synchronous machines," IEEE Trans. Ind. Electron., vol. 59, no. 6, pp. 2438-2447, Jun. 2012

[29] H.S. Ryu, I.H. Lim, J.H. Lee, S.H. Hwang, and J.M. Kim, "A dead time compensation method in voltage-fed PWM inverter," in Proc. IEEE 41st Ind. Applicat. Society Annual Meeting, Oct. 2006, vol. 2, pp:911-916.

[30] H. B. Zhao, Q. M. Wu, and A. Kawamura, "An accurate approach of nonlinearity compensation for VSI inverter output voltage," IEEE Trans. Power Electron., vol. 19, no. 4, pp. 1029-1035, 2004.

[31] A.M.N. Lima, C.B. Jacobina, and E.B.D.S Filho, "Nonlinear parameter estimation of steady-state induction machine models," IEEE Trans. Ind. Electron., vol. 44, no. 3, pp. 390-397, Jun. 1997.

[32] M. Wlas, Z. Krzeminski, and H.A. Toliyat, "Neural-network-based parameter estimations of induction motors," IEEE Trans. Ind. Electron., vol. 55, no. 4, pp. 1783-1794, Apr. 2008.

[33] B. Widrow, and M.A. Lehr, "30 years of adaptive neural networks: percentron, MAdaline, and backpropagation," Proc. of the IEEE, vol. 78, no. 9, pp. 1415-1442, 1990

[34] Y. Park, and S.K. Sul, "A novel method utilizing trapezoidal voltage to compensate for inverter nonlinearity," IEEE Trans. Power Electron. vol. 27, no. 12, pp. 4837-4846, Dec. 2012. 
[35] K.H. Kim, "Simple on-line compensation scheme of nonlinearity in inverter-fed PMSM drive using MRAC and co-ordinate transformation," IET Electron. Letters, vol. 47, no. 8, pp. 514-515, 2011.

[36] G. Pellegrino, P. Gulielmi, E. Armando, and R.I. Bojoi, "Self-commisioning algorithm for inverter nonlinearity compensation in sensorless induction motor drives," IEEE Trans. Ind. Applicat., vol. 46, no. 4, pp. 1416-1424, Jul./Aug. 2010.

[37] R. Krishnan, and P. Vijayraghavan, "Fast estimation and compensation of rotor flux linkage in permanent magnet synchronous machines," in Proc. IEEE International Symposium on Ind. Electron., 1999, vol. 2, pp. 661-666.

[38] T. Sebastian, "Temperature effects on torque production and efficiency of PM motors using NdFeB magnets," IEEE Trans. Ind. Applicat., vol. 31, no. 2, pp. 353-357, Mar./Apr. 1995.

[39] M. Kovacic, Z. Hanic, and M. Vrazic, "Design of large synchronous turbo-generator monitoring system," in Proc. IEEE International Conf. Electrical Machines, 2012, pp. 1629-1634.

[40] W. le Roux, R.G. Harley, and T.G. Habetler, "Detecting rotor faults in low power permanent magnet synchronous machines," IEEE Trans. Power Electron., vol. 22, no. 1, pp. 322-328, Jan. 2007.

[41] K.D. Hoang, Z.Q. Zhu, and M.P. Foster, "Influence and compensation of inverter voltage drop in direct torque-controlled four-switch three-phase PM brushless AC drives," IEEE Trans. Power Electron., vol. 26, no. 8, pp. 2343-2357, Aug. 2011.

[42] N. Urasaki, T. Senjyu, K. Uezato, and T. Funabashi, "An adaptive dead-time compensation strategy for voltage source inverter fed motor drives," IEEE Trans. Power Electron., vol. 20, no. 5, pp. 1150-1160, Sep. 2005.

[43] H. Liu, Z.Q. Zhu, E. Mohamed, Y. Fu, and X. Qi, "Flux-weakening control of nonsalient pole PMSM having large winding inductance, accounting for resistive voltage drop and inverter nonlinearities," IEEE Trans. Power Electron., vol. 27, no. 2, pp. 942-952, Feb. 2012.

[44] M. Hinkkanen, T. Tuovinen, L. Harnefors, and J. Luomi, “A combined position and stator-resistance observer for salient PMSM drives: design and stability analysis," IEEE Trans. Power Electron., vol. 27, no. 2, pp. 601-609, Feb. 2012.

[45] Y. He, Y. Wang, Y. Feng, and Z. Wang, "Parameter identification of an induction machine at standstill using the vector constructing method," IEEE Trans. Power Electron., vol. 27, no. 2, pp. 905-915, Feb. 2012.

[46] F.C. Dezza, G. Foglia, M.F. Iacchetti, and R. Perini, “An MRAS observer for sensorless DFIM drives with direct estimation of the torque and flux rotor current components," IEEE Trans. Power Electron., vol. 27, no. 5, pp. 2576-2584, May 2012.

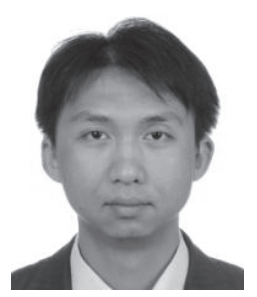

motor drives.

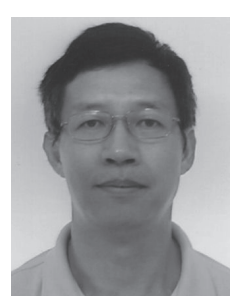

Z. Q. Zhu (M'90-SM'00-F'09) received the B.Eng. and M.Sc. degrees in electrical and electronic engineering from Zhejiang University, Hangzhou, China, in 1982 and 1984, respectively, and the Ph.D. degree in electrical and electronic engineering from the University of Sheffield, Sheffield, U.K., in 1991. He is currently a Professor of Electrical Machines and Control Systems at University of Sheffield, and Head of the Electrical Machines and Drives Research Group. His major research interests include design and control of permanent magnet brushless machines and drives, for applications ranging from automotive engineering to renewable energy.

Kan Liu received the B.Eng. and Ph.D. degrees in automation (control theory and control engineering) from Hunan University, Changsha,

Electronic and Electrical Engineering, the University of Sheffield, Sheffield, U.K. His research interest focuses on the control of brushless $\mathrm{AC}$ 